\title{
Estigma social y adopción internacional en España. ¿Es la familia adoptiva un modelo familiar menos «auténtico» que los basados en lazos biológicos?
}

\author{
María José Rodríguez-Jaume \\ Diana Jareño Ruiz \\ Universidad de Alicante. Facultad de Ciencias Económicas y Empresariales. \\ Departamento de Sociología I \\ mj.rodriguez@ua.es; diana.jareno@ua.es
}

Recepción: 19-02-2014

Aceptación: 24-10-2014

\section{Resumen}

En España, el fenómeno de las adopciones internacionales irrumpe en la década de 1990. En 2004, se convirtió en el segundo país del mundo que las llevaba a cabo. Con el objetivo de incrementar el conocimiento sociológico sobre la familia adoptiva internacional española, se realizó la encuesta a través de web titulada Las familias adoptivas y sus estilos de vida. A partir de las respuestas ofrecidas por 230 madres y padres adoptivos, se dibuja el perfil sociodemográfico de sus hogares. Estos se caracterizarían por contar con progenitores con elevado nivel formativo, no adscritos a ninguna religión, que defienden políticas de izquierdas y que comparten un sistema de valores posmodernos respecto a la institución familiar. La identificación de la estructura doméstica según su tipo de alianza (biparental o monoparental) y su tipo de filiación (adoptiva o mixta) nos permite situar a la adopción contemporánea como una opción de filiación elegida y no, exclusivamente, como alternativa ante la imposibilidad de tener hijos biológicos. Adicionalmente, los resultados arrojados por la encuesta nos permiten adentrarnos en uno de los aspectos menos abordados en el estudio sociológico de la familia adoptiva: el papel de las actitudes sociales hacia la adopción y su impacto en aquella. La mayoría de los encuestados perciben el estigma social del que es objeto su familia adoptiva, pues, desde su punto de vista, la sociedad las considera como una forma de hogar menos satisfactoria que la basada en lazos biológicos.

Palabras clave: familia interracial; familia adoptiva transnacional; nuevas formas de hogar; encuesta en línea; estigmatización; sanciones sociales; actitudes de la comunidad. 
Abstract. Social stigma and international adoption in Spain: Is the adoptive family a less 'authentic' (family) model than those based on biological ties?

In Spain, the phenomenon of international adoptions began in the nineties, becoming the second country in the world in number of international adoptions in 2004. With the aim of increasing knowledge about the international adoptive Spanish family, the computer-assisted online survey Adoptive families and their lifestyles was distributed. From the responses given by 230 adoptive mothers and fathers, the socio-demographic profile of adoptive Spanish families becomes visible. These families are characterized for having parents with a high educational level, who do not ascribe to any religion, defend left-wing politics, and share a system of postmodern values regarding the family institution. The identification of the family structure according to the type of alliance (two-parent family or single-parent family) and type of filiation (adoptive or mixed) allows us to place contemporary adoption as an option of chosen filiation, and not only and exclusively as an alternative to the impossibility of having biological children. In addition, the results derived from the survey allow us to delve deeper into one of the least tackled aspects in the sociological study of the adoptive family: the role of social attitudes towards adoption and their impact on the adoptive family. Most of the survey respondents are aware of the stigma their adoptive family represents, since from their point of view, society considers them as a less satisfactory form of family than those based on biological bonds.

Keywords: interracial family; adoptive transnational families; new family forms; online survey; stigmatization; social sanctions; community attitudes.

\section{Sumario}

1. El baby boom de las adopciones internacionales en España

2. Hacia una sociología de las adopciones en España

3. Marco teórico: la estigmatización de la familia adoptiva

4. Metodología: la encuesta Las familias adoptivas y sus estilos de vida
5. Sociodemografía de las madres y de los padres adoptivos

6. Sociodemografía de las familias adoptivas

7. La percepción del estigma social

en las familias adoptivas

Conclusiones

Referencias bibliográficas

\section{El baby boom de las adopciones internacionales en España}

El fenómeno de las adopciones internacionales en España se presenta con retraso en relación con nuestros países europeos vecinos, aunque con una intensidad sin parangón. Mientras que la tradición en adopción internacional en Holanda, en Francia y en los países nórdicos se sitúa en la década de 1970 (Adroher, 1998: 238-239), en España no será hasta los años noventa cuando esta opción de filiación adquirirá protagonismo. Desde entonces, la tendencia dibujada por el flujo de adopciones internacionales es contraria a la evolución seguida por la adopción nacional: en 1990, el peso de las adopciones internaciona- 
les en nuestro país, respecto al conjunto de las adopciones realizadas, apenas alcanzaba el 2\% (Adroher, 1998: 286); en 2011 (últimos datos disponibles), el $76,8 \%$ de las adopciones registradas en España se realizaron en el extranjero (INE, 2014). En 2004, con 5.541 adopciones en el extranjero, España se convierte en el segundo país del mundo - después de EE. UU.- en adopciones internacionales (Selman, 2006: 189, 2012) ${ }^{1}$.

El año 2004 supone un punto de inflexión en la tendencia del flujo de adopciones internacionales en España. Desde entonces, esta ha ido descendiendo hasta situarse, en 2011, en 2.573 adopciones en el extranjero (INE, 2014). Este descenso, próximo al 54\% respecto a 2004, ha sido compartido con el resto de países a excepción de Italia (Selman, 2009: 2012). La ralentización mundial del flujo de adopciones en el extranjero se explica a partir de los efectos derivados de la extensión internacional de políticas para la infancia. Así, países como China, Rusia y Ucrania, de los que tradicionalmente procedía el mayor número de niñas y niños para la adopción internacional, han endurecido las condiciones para iniciar sus procesos de ahijamiento, al mismo tiempo que van introduciendo medidas dirigidas a estimular la adopción interna (SSI/CIR, 2007). Estas medidas han devenido en un cambio en las características sociodemográficas de las niñas y de los niños susceptibles de ser adoptados y que, actualmente, no se ajustarían a los requerimientos de madres y padres españoles que desean, con la adopción, vivir la experiencia de la maternidad y la paternidad con un hijo de corta edad y sin necesidades especiales ${ }^{2}$ (Adoptantis, 2011). Así, y teniendo en cuenta que el incremento de los ahijamientos de niños con necesidades especiales ha sido uno de los cambios más significativos que ha experimentado el flujo de adopciones internacionales a escala global, en España, su peso es muy exiguo: en 2009 , el porcentaje de niñas y niños adoptados con necesidades especiales se situó en el 9\%, muy por debajo del 66\% alcanzado en los Países Bajos (Selman, 2012).

A pesar de la reducción del flujo de adopciones internacionales, y pese a que el número relativo de las familias adoptivas en España es pequeño, la adopción ofrece interesantes retos para la reflexión y el avance en la sociología de la familia. En primer lugar, el estudio de la adopción ofrece la oportunidad sociológica de abordar rutas no tradicionales en la constitución de unidades familiares, reivindicando, para el catálogo de «nuevos tipos familiares», aquellas que desafían al modelo normativo y «naturalizado» de la familia biológica. En segundo lugar, y dado que, con la adopción internacional, se constituyen

1. En 1998, la tasa bruta de adopciones (número de adopciones por cada 100.000 habitantes) fue de 3,8, lo cual situa a España en el décimo lugar. Seis años después, en 2004, solo fue superada por Noruega (con una tasa del 15,4). La tasa en 2011 fue de 5,4.

2. Junto a los procesos ordinarios de adopción internacional, algunos países desarrollan programas específicos para promover el ahijamiento de niños y niñas que tienen mayor dificultad para ser adoptados, esto es, con necesidades especiales (padecen o han padecido alguna enfermedad, cuentan con alguna discapacidad, tienen más de cinco años y/o se trata de grupos de hermanos). Estos programas son más flexibles en cuanto a los requisitos exigibles a los padres adoptivos y reducen tanto el tiempo de espera de la asignación, como las tasas del proceso administrativo. Específicamente, el programa «Pasaje verde» es el que regula la adopción de niños y niñas chinas con necesidades especiales. 
familias interraciales, el estudio de familias adoptivas en España se convierte, como advierten Haugaard y Hazan (2003), en un «experimento natural» con el que abordar la cercanía racial, tradicionalmente circunscrita a la observación de los matrimonios y las parejas interraciales. Por último, cabe anotar que la ausencia de investigación sociológica propicia que la adopción, como realidad terminológica y social, sea significada a través del imaginario social y, como han señalado Jociles y Charro (2008), desde la práctica profesional vinculada con la gestión del proceso de la adopción. Qué es y qué significa la adopción para sus protagonistas difiere de la opinión y de la valoración que la Administración y la sociedad españolas hacen de dicho proceso en general, lo que conlleva que se alimente una concepción de la familia adoptiva basada en estereotipos y tabúes alejados de su realidad y se estigmatice y se devalúen, en consecuencia, otros modelos de hacer familia.

\section{Hacia una sociología de las adopciones en España}

El camino hacia una sociología de la adopción apenas se ha iniciado. Fisher (2003) y, más recientemente, Conn (2013) han subrayado la paradójica escasa presencia de la familia adoptiva como categoría de análisis en las publicaciones académicas vinculadas a la sociología de la familia en un entorno, el norteamericano, líder en adopciones. Esta ausencia en la literatura especializada, sin embargo, contrasta con el interés que la Administración norteamericana mantiene por conocer esta nueva realidad doméstica: el censo de población norteamericano incluye, desde su edición del año 2000, la categoría "hijo o hija adoptado» (Kreider, 2003).

En España, la irrupción relativamente reciente del fenómeno de las adopciones internacionales ha motivado que la investigación se haya centrado en estudiar la incidencia de problemas de conducta, adaptación, integración e identidad, así como en analizar las carencias médico-sanitarias de los niños adoptados (Amorós, 1986; March, 1993; Palacios, 1997; Palacios et al., 2005). La inclusión de artículos dedicados a la «familia adoptiva» en las publicaciones sociológicas españolas no difiere del panorama norteamericano descrito. La aproximación sociológica más desarrollada ha sido la que ha abordado la adopción como proceso histórico-jurídico (Ocón y Castón, 2002; Ocón, 2003, 2004, 2006a). En ella, se incluyen referencias estadísticas procedentes de los organismos oficiales que, al no seguir en su registro las recomendaciones de Naciones Unidas ${ }^{3}$ (ONU,

3. Naciones Unidades recomienda que el registro de las adopciones internacionales se estructure en torno a tres bloques de información: (1) características del registro de la adopción en el país de origen y (2) en el de destino (país, lugar de residencia, tipo de adopción, fecha de solicitud, de aceptación, de entrada en vigor, de salida y de llegada) y (3) características de las personas involucradas en la adopción (sexo, edad, lugar de residencia, nacionalidad, número de hijas e hijos biológicos antes de la adopción y estado civil). Los dos primeros bloques permiten realizar el estudio detallado del flujo de adopciones, mientras que el tercero ofrece la posibilidad de profundizar tanto en las características sociodemográficas de los padres biológicos, de los adoptivos y de los niños adoptados, como en la estructura de la familia de nacimiento y adoptiva. 
2009: 141-148), no permiten profundizar en la familia adoptiva. Una segunda estrategia de investigación ha venido de la mano del enfoque cualitativo desde el que la familia adoptiva se analiza a partir de variables psicosociales (Ocón, 2002 y 2008). La reflexión teórica sobre el alcance de incluir a las familias adoptivas en el catálogo de nuevas formas de hogar ocupa un lugar testimonial (Ocón, 2006b), y de fecha reciente es la inclusión de la familia adoptiva en manuales dedicados a los hogares en España (Marre, 2011).

La presencia del fenómeno de las adopciones en las encuestas sociológicas españolas puede calificarse de residual y dependiente del contexto político. El primer sondeo de opinión del CIS en el que se incluyeron preguntas relacionadas con el acogimiento y la adopción se realiza en 1990 (Juste et al., 1991). Su propósito fue recabar el interés y la actitud de los españoles frente al acogimiento familiar, figura que consideró la Ley 21/87 y con la que se modificaba la legislación vigente en materia de adopción. Con posterioridad, en 2004, y previamente a la aprobación de la ley de matrimonios del mismo sexo (Ley 13/2005), el CIS interrogó a la población española sobre diversos aspectos vinculados con los derechos en materia de adopción de las parejas de hecho (CIS, 2004a) y de las parejas homosexuales (CIS, 2004a y 2004b). Paradójicamente, han sido las encuestas de fecundidad realizadas en España las que han incluido, desde la Encuesta de Fecundidad y Familia (FFS/ONU), de 1995, la categoría "hijo o hija adoptado» (CIS, 1995). En su edición de 2006, las 44 mujeres adoptivas que recoge la muestra fueron definidas como una «subpoblación singular» (Delgado, 2007: 31).

La encuesta Las familias adoptivas y sus estilos de vida se realizó con el objetivo de incrementar el conocimiento sociológico de uno de los nuevos tipos familiares que mayor visibilidad y relevancia social ha adquirido en la posmodernidad y para el que la aproximación sociológica en España es todavía incipiente. En este artículo, se expone un avance de los resultados obtenidos. El apartado cinco se centra en la identificación del perfil sociodemográfico de las madres y de los padres adoptivos que participaron en la investigación y, en el seis, se realiza la descripción de la familia adoptiva. En el apartado siete, se estudia la percepción del estigma social desde el punto de vista de las propias familias adoptivas, un aspecto escasamente explorado en España y de gran impacto en sus dinámicas internas. En el último apartado, se destacan los hallazgos que suponen una aportación relevante para la sociología de la familia, así como las posibles líneas futuras de investigación.

\section{Marco teórico: la estigmatización de la familia adoptiva}

Una de las características que definen como «nuevos» a modelos familiares que históricamente han existido es su reconocimiento legal y social (Ruiz, 2004). Actualmente, las sociedades occidentales no solo equiparan legalmente la filiación biológica y la adoptiva, sino que manifiestan una elevada aceptación social hacia la misma. En España, un 70,5\% de la población se imagina adoptando a un niño extranjero (Alberdi y Escario, 2003: 84). Sin embargo, y a pesar de 
que la adopción ha adquirido notoriedad y una gran aceptación social, una minoría la elige como forma de filiación.

El disenso que se produce entre actitudes y comportamientos sobre la adopción se viene explicando por la conjunción de varios factores. En primer lugar, la investigación ha desvelado que los padres y las madres que tienen hijos adoptados comparten una serie de rasgos sociodemográficos que, por un lado, les define y, por otro, les diferencia del subgrupo poblacional, así como que no convierten su actitud positiva hacia la adopción en un comportamiento efectivo. Estos quedarían caracterizados como una subpoblación que accede a la adopción entre los 30 y los 44 años, mayoritariamente casada, con elevada formación y alto poder adquisitivo (Ishizawa y Kubo, 2013; Jones, 2008; Palacios et al., 2005). La literatura especializada también ha anotado que la población más favorable a la adopción de niños compartiría con mayor intensidad los valores posmodernos de la cultura familiar, esto es, mostraría una mayor tolerancia hacia "comportamientos desviados respecto al modelo de "familia normal parsoniano"” (Meil, 1999: 17), además de otorgar mayor centralidad a los hijos en su vida doméstica (Mohanty, 2013; Tybjee, 2003). Tybjee (2003) apreció que la identificación con la comunidad gay, lesbiana, bisexual y transgenérica influye en la disposición hacia la adopción más que la afiliación religiosa, la cercanía con el movimiento ecologista o el posicionamiento político. Las identificaciones religiosa y política explicarían una mayor actitud positiva hacia la adopción, pero no estarían relacionadas con comportamientos efectivos de la población frente a la adopción (Tybjee, 2003; Van Laningham et al., 2012).

En segundo lugar, los estudios que han abordado el fenómeno de la adopción atendiendo al papel de las actitudes sociales que provoca han subrayado su carácter estigmatizante ${ }^{4}$. Desde este enfoque, la brecha entre actitudes y comportamientos frente a la adopción obedece a que esta no es considerada socialmente como una forma de filiación satisfactoria. En este sentido, la aceptación generalizada de la población frente a la adopción estaría reflejando el efecto de la deseabilidad social ante un tema comprometido (Miall, 1996: 315). La hegemonía en Occidente de un sistema de parentesco definido a partir de la ideología de la familia genética conlleva que las formas de hogar no constituidas a partir de vínculos consanguíneos hayan sido socialmente construidas como «anormales»" (Bernardes, 1985) o como una desviación estigmatizada de

4. Desde la tradición goffmaniana, el término estigma se aplica para designar a un atributo desacreditador (manifiesto y conocido) o desacreditable (oculto y desconocido). A partir de la identificación de los símbolos de estigma, se construye una teoría del estigma o una ideología que, socialmente, no solo da cuenta de la condición de inferioridad de quienes los portan, sino que también servirá para justificar su discriminación o su no aceptación en un intercambio social corriente. La finalidad social al identificar el atributo estigmatizante no es otra que la de confirmar a los normales, así como a la ideología que los sustenta (Erving Goffman (1963), Estigma: La identidad deteriorada, Buenos Aires-Madrid, Amorrortu, 2010, p. 15).

5. Siguiendo a Goffman, en contextos de un intercambio social corriente, son normales «todos aquellos que no se apartan negativamente de las expectativas particulares que están en discusión» (ibídem, p. 17). 
la norma social (Kressierer y Bryant, 1996). La sociedad identifica en el nexo biológico el requisito previo de una "auténtica» unión y relación filial. Las emociones experimentadas, el valor de los hijos y la validez de la crianza adoptiva no son tan buenos o reales como los que manifiestan las familias biológicas, de ahí que las familias adoptivas sean vistas como "de segunda» (Miall, 1987), como la «segunda opción» (March y Miall, 2000; Wegar, 2000) o el «último recurso" para ser padres (Miall, 1986). Alberdi y Escario (2007), desde un enfoque cualitativo, han subrayado la diferenciación que los jóvenes españoles realizan entre la paternidad biológica y la adoptiva, en base a la preeminencia de criterios biológicos.

La heterogeneidad que asume la propia familia adoptiva provoca que su exposición social a sanciones informales difiera según su estructura de hogar, atributo desacreditador manifiesto, en contextos de interacción social. Respecto a su tipo de filiación, Miall (1987) ha sugerido que la percepción de la discriminación variará en función de que la familia adoptiva integre o no a hijos biológicos. Los hogares que solo cuentan con hijos adoptivos estarían más estigmatizados, al ser valorados más negativamente, pues afrontarían situaciones en las que se ha presumido que la llegada del hijo adoptivo ha sido motivada por la infertilidad, atributo que puede ser deshonroso (Miall, 1986). Mientras, la adopción de niños por parte de familias que ya cuentan con hijos biológicos puede comportar connotaciones positivas, puesto que, socialmente, el proceso adoptivo se vincula con los valores de generosidad y altruismo.

Atendiendo al tipo de alianza en la familia adoptiva, la investigación subraya que la heterosexualidad y la biparentalidad institucionalizada estratifica tanto a los padres del mismo sexo como a las madres solteras, lo que conllevaría una fuente de estigma adicional. Raleigh (2012) ha señalado que gays, lesbianas y familias monoparentales ocupan una posición marginal en el mercado de la adopción internacional, al asignarles, frecuentemente, niños con necesidades especiales. Estas estructuras domésticas son sometidas a prácticas discriminatorias explícitas e implícitas (Falletti, 2014; Jociles et al., 2012; Raleigh, 2012). Explícitamente, porque la regulación internacional en materia de adopción privilegia a las parejas heterosexuales, ya que no todos los países admiten que gays, lesbianas y personas solas adopten, e, implícitamente, porque, aún en los casos en los que se les reconoce el derecho a adoptar, las evaluaciones de idoneidad y elegibilidad se rigen por criterios prejuiciosos en los que se toma como referente normativo a la familia nuclear biparental y heterosexual.

\section{Metodología: la encuesta Las familias adoptivas y sus estilos de vida}

La encuesta Las familias adoptivas y sus estilos de vida explora las características, las opiniones, las actitudes y los comportamientos de las familias españolas que han adoptado en el extranjero. El cuestionario se estructuró en torno a ocho secciones temáticas que operacionalizaban los conceptos teóricos que, desde la sociología, se vienen aplicando en el estudio de los hogares, así como cuestiones específicas sobre el proceso de adopción, la familia adoptiva, la familia adoptiva interracial y 
la estigmatización de la familia adoptiva. El diseño del cuestionario finalizó con el pretest que se desarrolló siguiendo el proceso de pruebas múltiples (Dillman, 2000).

Ante la inexistencia de un registro de familias adoptivas desde el que, a modo de marco muestral, se pudiera acceder a ellas, y desde la consideración de que el fenómeno de las adopciones se ha convertido en un fenómeno en línea (Wahl et al., 2005), proliferando tanto sitios web informativos como redes virtuales de comunicación, asociación y apoyo emocional (Marre, 2004), el cuestionario fue administrado en línea, con lo cual se inscribía, específicamente, en las encuestas denominadas Computer Assisted Web Interviewing $(\mathrm{CAWI})^{6}$. Para la captación de madres y padres adoptivos, se aplicó un protocolo de invitación múltiple (Couper et al., 2001). Cho y LaRose (1999) sugieren cursar la invitación a los "líderes», con el fin de evitar los inconvenientes metodológicos y éticos de acceder directamente a las listas de correo de libre acceso, creadas para proveer información y apoyo emocional. Por ello, se contactó con quienes presidían las asociaciones de familias adoptantes. Finalmente, diecinueve asociaciones de familias adoptivas colaboraron con la investigación, dando a conocer la investigación y la encuesta a través de sus páginas, listas de distribución, blogs y redes sociales respectivas.

Durante los meses en que estuvo activada la encuesta (desde julio hasta septiembre de 2012), 835 madres y padres adoptivos accedieron al sitio web en el que se alojó. El diseño en línea permitía interrumpir la autocumplimentación del cuestionario y retomarlo en aquella sección en la que se había dejado. El $28,6 \%$ de quienes accedieron a la encuesta (239 casos) cumplimentaron la totalidad del cuestionario, el resto lo fue abandonando en distintos momentos. Después de realizar la depuración de los datos, y eliminados los cuestionarios que no superaron las preguntas de consistencia, se obtuvo una muestra no probabilística por autoselección (Couper, 2000) de 230 padres adoptivos. La muestra está compuesta mayoritariamente por madres adoptivas (83\%). Estas, en el momento de la administración de la encuesta, tenían una edad media de 44,1 años, mientras que la de los padres adoptivos fue de 46,4 años.

La muestra no probabilística obtenida, al no ser representativa de las madres y de los padres adoptivos, impide la generalización de sus hallazgos. Esta limitación sitúa los análisis efectuados en la exploración de la realidad observada, lo cual permite avanzar en el estudio de la familia adoptiva española a través de la comparación estadística con los estudios realizados, fundamentalmente, en el ámbito internacional. Particularmente, los resultados que se presentan en los apartados que siguen tienen por finalidad contribuir al conocimiento sociológico de tres aspectos específicos: descripción del perfil sociodemográfico de los adoptantes españoles en el extranjero, descripción de su estructura familiar e identificación de la percepción de su estigma social. A partir de las

6. El sistema CAWI es un método basado en Internet Data Collection (IDC). Se sirve de la red para la administración del cuestionario. La gestión de las respuestas ofrecidas se realiza a través del servidor en el que se encuentra alojada la encuesta y se almacenan en la base de datos de un archivo TXT. compatible con el paquete estadístico SPSS. 
evidencias sociológicas, los análisis efectuados han tenido en consideración las siguientes hipótesis de investigación:

1. Respecto al perfil sociodemográfico de los padres adoptivos españoles, estos mostrarían rasgos identificativos y diferenciales respecto al conjunto de la población.

2. Adicionalmente, y en relación con la población en general, estos compartirían con mayor intensidad los valores posmodernos de la cultura familiar y otorgarían una mayor centralidad a los hijos en su vida familiar.

3. Dado que la notoriedad y la relevancia social que la adopción ha adquirido en la sociedad española se enmarca en un proceso general de mayor libertad individual en el modo de plantear la vida familiar (Meil, 1999, 2006), las familias adoptivas mostrarán pluralización en su estructura familiar, tanto en su sistema de alianza como en el de filiación.

4. Las familias adoptivas, al transgredir la ideología de la familia genética que define el sistema de parentesco en Occidente, serán objeto de diferenciación social.

5. Y, particularmente, la percepción de la estigmatización social será mayor entre las familias adoptivas de filiación adoptiva —en las que se presupone que no pueden tener hijos biológicos- y entre las familias que transgreden la heterosexualidad y la biparentalidad institucionalizada.

Los análisis univariados y bivariados que se presentan se inscriben en una investigación de carácter descriptivo. El análisis univariable se utilizó para la descripción sociodemográfica de las madres y de los padres adoptivos, así como para la identificación de sus estructuras familiares (objetivos 1 y 2). Cuando se dispone de datos, las variables analizadas son comparadas con los resultados arrojados por el conjunto de la población española (CIS, 2004b, 2010). Por su parte, el análisis bivariado nos acerca a la percepción del estigma social entre las familias adoptivas (objetivo 3). En este caso, las tablas de contingencia permiten realizar la comparación entre subgrupos: familias adoptivas con filiación adoptiva y mixta y familias adoptivas biparentales y monoparentales.

\section{Sociodemografía de las madres y de los padres adoptivos}

Las madres y los padres adoptivos internacionales de la muestra se describen en el cuadro 1. Al comparar su patrón sociodemográfico con el dibujado por el conjunto de la población española (CIS, 2010), se aprecian sus características identificativas y diferenciales y que, en sentido general, corresponden a las ya señaladas en adopción internacional.

Una de las características compartidas por la población adoptante es su elevado capital humano. En la muestra de familias adoptivas, la presencia de madres y padres con niveles de formación superiores triplica a la de la población en general. No obstante, y a pesar de que este sea uno de sus rasgos más identificativos, es posible que esté sobrerrepresentado en una muestra auto- 
Cuadro 1. Características sociodemográficas de las madres y de los padres adoptivos (FAMADOP, 2012) y de la población española (POBLACION, 2010)*

\begin{tabular}{|c|c|c|}
\hline & FAMADOP $_{2012}$ & POBLACIÓN $_{2010}$ \\
\hline \multicolumn{3}{|l|}{ Estado civil ${ }^{1}$ (\%) } \\
\hline Soltero o soltera & 10,0 & 30,0 \\
\hline Casado o casada & 83,5 & 56,9 \\
\hline Casado o casada para facilitar el proceso de adopción & 14,3 & - \\
\hline Viudo o viuda & 0,4 & 7,3 \\
\hline Separado o separada legalmente & 3,9 & 5,6 \\
\hline Convivo con pareja & 1,3 & - \\
\hline Con pareja sin convivencia & 0,9 & - \\
\hline \multicolumn{3}{|l|}{ Nivel de estudios ${ }^{2}(\%)$} \\
\hline Primario & 9,9 & 56,3 \\
\hline Medio & 17,4 & 22,8 \\
\hline Superior & 72,7 & 20,7 \\
\hline \multicolumn{3}{|l|}{ Ocupación ${ }^{3}$ (\%) } \\
\hline Dirección & 6,1 & 6,6 \\
\hline Técnicos y profesionales científicos e intelectuales & 34,3 & 12,2 \\
\hline Técnicos y profesionales de apoyo & 11,7 & 13,9 \\
\hline Empleados tipo administrativo & 19,1 & 4,1 \\
\hline $\begin{array}{l}\text { Trabajadores de servicios de restauración, personales, } \\
\text { protección y vendedores }\end{array}$ & 6,1 & 15,0 \\
\hline \multicolumn{3}{|l|}{ Percepción situación económica personal (\%) } \\
\hline Muy buena y buena & 63,5 & 32,8 \\
\hline Regular & 29,5 & 48,4 \\
\hline Mala y muy mala & 7,0 & 17,9 \\
\hline \multicolumn{3}{|l|}{ Autoubicación ideológica ${ }^{4}$} \\
\hline Izquierda (1-2) & 32,7 & 7,3 \\
\hline$(3-4)$ & 30,9 & 22,9 \\
\hline Centro (5-6) & 15,6 & 30,1 \\
\hline$(7-8)$ & 10,9 & 10,5 \\
\hline Derecha $(9-10)$ & 3,9 & 2,5 \\
\hline \multicolumn{3}{|l|}{ Práctica religiosa ${ }^{5}$} \\
\hline Católica practicante & 15,2 & 732 \\
\hline Católica no practicante & 33,9 & 73,2 \\
\hline Protestante & 0,9 & - \\
\hline Otra & 1,7 & - \\
\hline Ateo o atea & 42,2 & 8,0 \\
\hline
\end{tabular}

Fuente: elaboración propia a partir de los datos de la encuesta Las familias adoptivas y sus estilos de vida (FAMADOP, 2012) y Barómetro de septiembre (CIS, 2010) (POBLACIÓN).

* Categorías para las que no se dispone de datos (-).

Las opciones de respuesta NS y NC se han excluido del cuadro.

1. Estado civil: separado/a legalmente $=$ separado/a legalmente y divorciado/a.

2. Nivel de estudios: primario = menos de 5 años de escolarización, educación primaria, ESO o bachiller elemental y formación profesional de grado medio; medio = bachillerato LOGSE y formación profesional de grado superior; superior = arquitectura o ingeniería técnica, diplomado, arquitecto o ingeniero superior, licenciatura, estudios de posgrado o especialización y doctorado.

3. Ocupación: las categorías recogidas representan al $77,3 \%$ de la muestra de madres y padres adoptivos y al $51,8 \%$ de la muestra del CIS.

4. Autoubicación política: esta variable en ambas encuestas está escalada de 1 a 10, en donde 1 indica la posición ideológica situada más a la izquierda y 10, la posición ideológica más a la derecha.

5. Práctica religiosa: la encuesta del CIS no diferencia entre católico practicante y no practicante e incluye las categorías «otra religión»y «no creyente». 
seleccionada a través de la red ${ }^{7}$. Se ha sugerido que la adopción internacional inhibe a la población con baja formación, pues se autopercibiría incapaz de hacer frente a los retos que impone una adopción en el extranjero (conocimiento del marco legal, viajes y estancia más allá del propio país, quizá un nuevo idioma y una cultura diferente). En este sentido concluyen las investigaciones que han abordado esta cuestión en España: en 1990, el 56\% de la población española consideraba la adopción como un proceso difícil, debido a la complicación de los trámites $(86 \%)$ y a las exigencias a las que la ley somete a quienes desean adoptar (75\%) (Juste et al., 1991: 83-86). Alberdi y Escario (2003: 59) añaden, a estos inconvenientes, la percepción social de que la adopción conlleva costes económicos importantes, de ahí que se suela vincular a familias con una posición económica elevada. En sintonía con esta última percepción, el análisis acerca de madres y padres adoptivos muestra que desempeñaban ocupaciones de mayor prestigio y estatus social, lo que justificaría que más de la mitad del conjunto de adoptantes, el doble respecto a la muestra de la población española, percibiera que su situación económica era «buena» o "muy buena».

La muestra de adoptantes se identificaría, y se diferenciaría respecto al conjunto de la población española, con posiciones políticas de izquierdas y con fuerte presencia del ateísmo. Van Laningham et al. (2012), en su análisis sobre los factores predictores de la adopción, han concluido que son las mujeres más religiosas las que más aceptan la adopción, pero las menos propensas a tomar medidas que les lleven a ella. Alberdi y Escario (2003: 57 y 84) observaron que el segmento de población que más se identificaba con una posible adopción futura era el que tenía menos de 45 años, que contaba con mayores niveles de educación y que se situaba políticamente más a la izquierda.

En el análisis sociodemográfico, el relativo al estado civil adquiere una relevancia especial, pues nos permite explorar, en las familias adoptivas, la diversificación de la estructura doméstica según el tipo de alianza, elemento definitorio de las nuevas formas familiares. Especialmente interesa la presencia de la monoparentalidad por elección ${ }^{8}$ y la cohabitación, pues estos tipos de hogar ejemplifican los modelos posmatrimoniales, al mismo tiempo que han experimentado un fuerte incremento en las dos últimas décadas. Inicialmente, los datos desvelan que la adopción internacional en España aparece enmarcada en un modelo tradicional matrimonial, dado que los padres adoptivos casados

7. El nivel educativo universitario de los padres españoles de adopción internacional alcanzaba, en el periodo 1997-2000, al 50\% de la muestra (Palacios et al., 2005: 58).

8. La monoparentalidad por elección define a la maternidad que se ejerce en solitario (fundamentalmente, por parte de mujeres) a partir de un proyecto planificado y originario. Esto es, no es sobrevenida (por divorcio, separación o viudedad) ni accidental (maternidad no buscada). La literatura especializada ha identificado una serie de rasgos comunes que también asumirían las madres adoptivas por elección de la muestra: edad elevada en el momento de ser madre (41,6 años), nivel formativo alto (el 82,6\% había alcanzado estudios superiores) y ocupaciones de mayor estatus (el 52,2\% desempeñaba puestos de dirección, así como trabajos técnicos e intelectuales) (A. M. ${ }^{a}$ Rivas, y M. ${ }^{a}$ I. Jociles (2013), «Las madres solas por

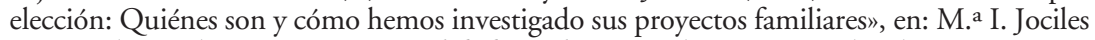
y R. Medina (eds.), La monoparentalidad por elección, Valencia, Tirant lo Blanc, 19-20). 
representan al 83,5\% de la muestra. Sin embargo, un análisis detallado de las categorías "soltero o soltera" y "convivencia con pareja» permite matizar esta primera apreciación descriptiva de corte transversal.

Como se aprecia en los datos, la soltería de la población española triplica a la de la muestra de adoptantes. Este elevado porcentaje se explica por el efecto de las muestras comparadas, pues la del CIS aglutina a la población española mayor de 18 años. El 10\% de los solteros de la muestra de adoptantes corresponde a 23 madres que, en el momento de la encuesta, vivían la experiencia de la adopción en solitario. No obstante, si consideramos su estado civil en el momento en el que iniciaron la convivencia con sus hijos adoptivos, la tasa de adopción internacional monoparental por elección alcanza el 12,2\%, nivel próximo al registrado en Finlandia (14\%) en 2003 (ONU, 2009: 101). El análisis retrospectivo no solo incrementa el peso atribuido inicialmente a la monoparentalidad por elección en la adopción internacional en España, sino que también constata su tendencia creciente, pues, para el quinquenio 20002004, su participación se estimó en el 9,4\% (González et al., 2007).

La cohabitación entre las familias de adopción internacional españolas se sitúa en el 1,3\%, indicador que evidenciaría la vigencia de la institución matrimonial. Sin embargo, el 14,3\% de las madres y de los padres adoptivos decidieron contraer matrimonio en cumplimiento de este requisito que exigen algunos países. Así, de no mediar este condicionante, la cohabitación en las familias adoptivas españolas se situaría en el 15,6\% y, en consecuencia, las parejas adoptivas casadas se reducirían al 69,2\%. Para este subconjunto de la muestra de adoptantes, el matrimonio resultaría como una estrategia de ajuste de las estructuras familiares a los dictados del mercado de adopción internacional. Este hecho pone en evidencia, tal y como ha sugerido Raleigh (2012), que la estructura familiar es un factor clave en la toma de decisiones y que, desde la óptica del funcionamiento del mercado de las adopciones, aparecen estratificados tanto los niños susceptibles de ser adoptados (Davis, 2011: 11-22)9 como los padres adoptivos potenciales.

\section{Sociodemografía de las familias adoptivas}

La adopción ha estado, hasta la década de los años setenta (Hoksbergen, 1998), vinculada al deseo adulto de formar una familia entre quienes no podían tener hijos biológicos. La infertilidad continúa hoy estrechamente relacionada con

9. Davis ha analizado las funciones que cumple la adopción a partir de las características compartidas por los niños que, en EE. UU., han sido adoptados en el extranjero y los que han sido adoptados en el propio país a través del sistema público. La función de la adopción internacional sería la de proveer «niños a familias» norteamericanas, mientras que la de la adopción nacional es la de proporcionar «familias a niños» que carecen de ella. En la adopción internacional, los niños adoptados son de corta edad y no tienen problemas de salud. Por su parte, en la adopción nacional, los niños adoptados comparten la etiqueta «difíciles de colocar", pues suelen tener más de seis años, proceden de minorías raciales y étnicas, tienen hermanos y presentan problemas de salud física o mental. 
la adopción. De hecho, es considerada como un predictor de la tendencia del flujo adoptivo (Jones, 2008; Vandivere et al., 2009). Sin embargo, en las últimas décadas, la adopción deja de ser exclusivamente una alternativa a la imposibilidad de acceder a la paternidad biológica (adopción tradicional) para convertirse en una opción de filiación elegida (adopción preferencial) (Anderson et al., 1993; Malm y Welti, 2010). La diversificación de las rutas de acceso a la adopción queda también impresa en las distintas estructuras a las que dan lugar las familias adoptivas según tipo de filiación.

Las 230 familias de adopción internacional que conforman la muestra cuentan con una media de 3,57 personas en el hogar. En su conjunto, las familias de la encuesta suman un total de 388 hijos (1,7 hijos por unidad familiar). De estos, el 19,1\% son biológicos, el 1\% son hijastros, el 0,3\% se encuentra en régimen de acogida y el 79,6\% está constituido por hijos adoptados. El 6,5\% de las adopciones se realizaron en España, esto es, 20 familias (8,7\%), además de adoptar en el extranjero, realizaron una adopción nacional. La edad en que se realiza la primera adopción en el extranjero es de 38,6 años. El hecho de que sea tan elevada se enmarca en el patrón europeo (ONU, 2009: 100) y se explica tanto por el retraso de la nupcialidad y la fecundidad en España como por el periodo que deben esperar para la asignación de un niño en adopción internacional y que, en el caso de los padres adoptivos de la muestra, fue de 5 años. El cuadro 2 profundiza en la estructura de las familias adoptivas según tipo de filiación, adoptiva o mixta, visibilizando las distintas rutas de acceso.

Las familias de la muestra están constituidas fundamentalmente por una filiación adoptiva. De las 176 familias que solo tienen hijos a través de la adopción, prevalecen aquellas que han vivido dicha experiencia una sola vez $(61,9 \%)$ o en dos ocasiones $(34,1 \%)$. Una única familia con filiación adoptiva cuenta con 4 hijos adoptivos. La diversificación de las situaciones que han originado la constitución de familias adoptivas se evidencia con la presencia de un $23,5 \%$ de familias con filiación mixta (hijos biológicos, hijastros y adoptivos). Cabe anotar que, para el 83,3\% de estas, la llegada de los hijos adoptivos acontece después de haber tenido hijos biológicos. Aunque con un carácter marginal, la muestra ha registrado dos hogares en los que la llegada de los hijos adoptivos se produce a partir de la reconstitución de la unidad familiar.

Cuadro 2. Estructura de las familias adoptivas según tipo de filiación

\begin{tabular}{lrr}
\hline & $\mathrm{n}^{\circ}$ & $\%$ \\
\hline Familia filiación adoptiva & 176 & 76,5 \\
Familia filiación mixta: & 43 & 18,7 \\
Familia hijos biológicos + adoptivos & 9 & 3,9 \\
Familia hijos adoptivos + biológicos & 2 & 0,9 \\
Familia hijastros + adoptivos & 230 & 100 \\
\hline Total
\end{tabular}

Fuente: elaboración propia a partir de los datos de la encuesta Las familias adoptivas y sus estilos de vida (2012). 
La estrecha vinculación que la adopción ha mantenido con la infertilidad ha provocado que, en el sentir popular, se generalice la idea de que la adopción es exclusivamente una vía de acceso para las personas que no han podido tener hijos biológicos. Los datos recabados en la encuesta señalan el disenso entre la construcción social que se ha hecho de la adopción y las motivaciones y los comportamientos que declaran sus protagonistas. Respecto a las motivaciones, tres son las razones fundamentales que llevaron a la adopción: «la adopción era su elección» (49,6\%), «la imposibilidad de tener un hijo biológico» $(40,4 \%)$ y «el sueño de formar una familia» (38,3\%). Los motivos esgrimidos contrastan con los manifestados por las 398 familias que adoptaron en Andalucía entre 1988 y 1993: el 60\% lo hizo porque no podía tener hijos biológicos, el 14\% ya conocía a los niños y el 11\% aludió a motivaciones altruistas ${ }^{10}$ (Palacios, 1997). Esta perspectiva diacrónica de las razones para la adopción dibuja la tendencia que sigue esta como vía de filiación electiva, lo cual resta protagonismo a la imagen social que la vincula con «la segunda mejor opción».

Las motivaciones expresadas por las familias adoptivas se trasladan al ámbito de los comportamientos: el 41,9\% de las familias que recibieron un diagnóstico de infertilidad no quisieron explorar las opciones que ofrece la medicina reproductiva.

En este contexto, cobra interés determinar si la pérdida de importancia que la descendencia consanguínea ha ido adquiriendo en los procesos de construcción identitaria individual y familiar es compartida tanto por las familias adoptivas con filiación mixta, como por las que cuentan con una filiación adoptiva. Para tal fin, determinamos la incidencia de los tratamientos de reproducción asistida en las familias adoptivas según su estructura de filiación. Los datos recogidos en el cuadro 3 apuntan hacia el mayor protagonismo que actualmente adquiere la adopción preferencial frente a la tradicional: para el $55,1 \%$ de las familias con filiación adoptiva, la adopción no llega después de haber agotado las vías por las que la medicina actual busca una reproducción biológica en los casos de infertilidad. En general, este subgrupo de padres adoptivos comparte tener un mayor nivel educativo y ocupacional que los que sí recurrieron a ellas y, fundamentalmente, este tipo de proyecto de hogar es protagonizado por las familias monoparentales, pues solo el $8,7 \%$ de ellas recurrieron a la medicina reproductiva.

Una de las características más definitorias de las familias posmodernas es la centralidad que los hijos adquieren en el hogar (Beck y Beck-Gernsheim, 2001: 189). Esta tendencia general se intensifica en el caso de las familias adoptivas. El 90,4\% de los encuestados piensa en sus hijos e hijas en primer lugar cuando evoca a su ámbito doméstico. Entre la población española, esta asociación se reduce al 65,9\% (CIS, 2010). La hegemonía que tienen los hijos en sociedades avanzadas obedece, en perspectiva histórica, a la pérdida de su interés material y al valor afectivo y psicológico que han ido adquiriendo. Siguiendo a Zelizer

10. En el análisis motivacional de las adopciones desde la perspectiva psicológica, el término altruista designa, en sentido general, a las adopciones que no se justifican por la infertilidad de los padres adoptivos, sino por cuestiones «solidarias». 
Cuadro 3. Incidencia de los tratamientos de reproducción asistida (TRA) según estructura de filiación familiar adoptiva

\begin{tabular}{lccl} 
Familias por tipo de filiación & $\begin{array}{c}\text { Familias } \\
\left(\mathbf{n}^{\circ}\right)\end{array}$ & $\begin{array}{c}\text { TRA } \\
\left(\mathbf{n}^{\circ}\right)\end{array}$ & $\begin{array}{l}\text { TRA } \\
(\%)\end{array}$ \\
\hline Familia hijos adoptivos & 176 & 79 & 44,9 \\
Familia hijos biológicos + adoptivos & 43 & 9 & 20,9 \\
Familia hijos adoptivos + biológicos & 9 & 3 & 33,3 \\
Familia hijastros + adoptivos & 2 & 1 & 50,0 \\
\hline Total & 230 & 92 & 40,0 \\
\hline
\end{tabular}

Fuente: elaboración propia a partir de los datos de la encuesta Las familias adoptivas y sus estilos de vida (2012).

(1985), los hijos hoy son objeto de sacralización: económicamente no tienen valor, pero son invalorables desde el punto de vista emocional. Nuevamente, entre las familias adoptivas, este patrón se acentúa, pues mientras que el 40,6\% de las mujeres españolas declararon que «tener hijos produce un sentimiento especialmente gratificante» (Delgado, 2007), entre las familias adoptivas la afirmación es compartida por el 50,8\%.

Como corolario del valor afectivo que representan los hijos en nuestra sociedad, la crianza adquiere un lugar destacado entre las funciones atribuidas a la familia (Beck-Gernsheim, 2003). El cuadro 4 recoge la opinión de la población española y la de las familias adoptivas respecto al papel que cumple la familia en la sociedad.

Cuadro 4. Funciones que cumple la familia en la sociedad actual (\%)

\begin{tabular}{lrrrrr}
\hline & \multicolumn{3}{c}{ Para la sociedad } & \multicolumn{2}{c}{ Para el encuestado } \\
& CIS $_{2004 \mathrm{~b}}$ & $\mathrm{CIS}_{2010}$ & FAMADOP & CIS $_{2004 \mathrm{~b}}$ & FAMADOP \\
\hline Criar y educar a los niños & 39,2 & 49,3 & 51,7 & 36,4 & 26,8 \\
y a las niñas & 18,3 & 27,7 & 28,9 & 38,0 & 62,4 \\
Proporcionar amor y afecto & 5,9 & 5,9 & 1,3 & 6,2 & 1,3 \\
$\begin{array}{l}\text { Cuidar de la salud de sus miembros } \\
\text { Asegurar la supervivencia }\end{array}$ & & & & & \\
de la especie humana & 7,8 & 1,9 & 2,0 & 1,6 & - \\
$\begin{array}{l}\text { Mantener los valores culturales } \\
\text { y morales }\end{array}$ & 13,4 & 7,3 & 4,0 & 7,2 & 1,3 \\
$\begin{array}{l}\text { Cuidar a los mayores } \\
\text { Proporcionar ayuda económica }\end{array}$ & 1,8 & 1,9 & - & 2,3 & - \\
$\begin{array}{l}\text { a los miembros que la necesiten } \\
\text { Otras }\end{array}$ & 4,6 & 1,5 & 1,3 & 0,7 & - \\
\hline Fue: el, & 1,5 & 1,3 & 6,7 & 2,7 & 6,7 \\
\hline
\end{tabular}

Fuente: elaboración propia a partir de los datos de la encuesta Las familias adoptivas y sus estilos de vida (FAMADOP, 2012); de la encuesta Opiniones y actitudes sobre la familia (CIS, 2004b), y el Barómetro de septiembre de 2010 (CIS, 2010).

* Los valores porcentuales del cuadro reproducen las respuestas ofrecidas en las distintas encuestas sobre el «papel más importante» o «en primer lugar» de la familia en la sociedad actual.

Las opciones de respuesta NS y NC se han excluido del cuadro. 
En opinión de los encuestados, la sociedad contempla cada vez más a la familia como una institución cuya principal función es criar y educar a los hijos. Las familias adoptivas, con un $51,7 \%$, son las que más participan de esta percepción. Sin embargo, para ellas, el principal papel que desempeñan es el de proporcionar amor y afecto: así lo opinó el $62,4 \%$ de familias adoptivas frente al 38\% de la población española (CIS, 2004b).

La familia adoptiva transgrede el modelo de familia nuclear basado en la filiación consanguínea, no solo a través del ejercicio de su maternidad y paternidad adoptivas, sino también a través de su opinión favorable hacia comportamientos tradicionalmente contemplados como desviados. A pesar de que, en la muestra de familias adoptivas, prevalecen las relaciones heterosexuales (el $81,7 \%$ de ellas convivía con una pareja de sexo distinto), no muestran oposición a que gays y lesbianas adopten, un comportamiento que se continúa sancionando entre la población española. El 84,8\% aprueba que gays y lesbianas adopten y el $86,5 \%$ opina que garantizan el bienestar del niño de la misma manera que lo hacen las personas heterosexuales. Este apoyo contrasta con la poca aceptación que, entre la población en general, suscita que adopten parejas del mismo sexo: lo tolera el $42,4 \%$ y un $63,7 \%$ admite que gays y lesbianas garantizan el bienestar de los hijos (CIS, 2004b). Las familias adoptivas ejemplifican la sentimentalización de la relación paternofilial que caracteriza a las familias posmodernas (Meil, 2006), contribuyendo, adicionalmente, al desarrollo de una ideología de familia más flexible, basada en el funcionamiento y no en la formación.

\section{La percepción del estigma social en las familias adoptivas}

La adopción, al desvincularse de la norma social de la reproducción biológica, puede convertirse en un descrédito potencial para madres, padres e hijos de difícil ocultación cuando el proceso implica el ingreso de hijos procedentes de otros países. No obstante, la literatura especializada ha puesto de manifiesto que la sociedad valora de forma disímil a las familias adoptivas en función de su estructura familiar según tipo de filiación (adoptiva o mixta) y alianza (biparental o monoparental). En consecuencia, están expuestas a distintos niveles de estigmatización social.

Inicialmente, Miall (1987) planteó que la adopción por parejas con filiación mixta es valorada más positivamente que la realizada por parejas con filiación adoptiva, dado el carácter estigmatizante que conlleva la infertilidad (Miall, 1986). Las opiniones vertidas por los encuestados en referencia a cómo son valorados como padres indican que, efectivamente, el hecho de contar o no con un hijo biológico les expone a evaluaciones sociales disímiles, pero no en el sentido señalado por la investigadora (cuadro 5). Son los padres adoptivos con filiación adoptiva los que experimentarían una valoración más positiva, al ser identificados como más «solidarios» (57,9\%); mientras que los padres adoptivos de filiación mixta serían contemplados como personas "caritativas» $\mathrm{y}$ "generosas» (50\%, respectivamente). En este sentido, y atendiendo al tipo 
Cuadro 5. Valores con los que la sociedad identifica a las madres y a los padres adoptivos según estructura familiar adoptiva (\%)*

\begin{tabular}{|c|c|c|c|c|}
\hline & \multicolumn{3}{|c|}{ Familias biparentales } & \multirow{3}{*}{$\begin{array}{l}\text { Familias } \\
\text { monop. }\end{array}$} \\
\hline & \multirow[b]{2}{*}{ Total } & \multicolumn{2}{|c|}{ Filiación } & \\
\hline & & Adoptiva & Mixta & \\
\hline Son más solidarias & 54,2 & 57,9 & 41,7 & 39,1 \\
\hline Son más caritativas & 48,1 & 47,6 & 50,0 & 43,5 \\
\hline Son más generosas & 47,6 & 47,0 & 50,0 & 56,5 \\
\hline Son más altruistas & 29,2 & 28,0 & 33,3 & 26,1 \\
\hline Tienen las mismas cualidades & 14,6 & 13,4 & 18,8 & 17,4 \\
\hline Se diferencian en otros aspectos & 6,1 & 6,7 & 4,2 & 17,4 \\
\hline
\end{tabular}

Fuente: elaboración propia a partir de los datos de la encuesta Las familias adoptivas y sus estilos de vida (2012).

* El cuadro recoge los porcentajes a partir del número de respuestas registradas a la pregunta de respuesta múltiple.

Las opciones de respuesta NS y NC se han excluido del cuadro.

de progenitura de las familias adoptivas, las percepciones valorativas vertidas por las monoparentales estarían más próximas a las de filiación mixta que a las de filiación adoptiva.

Este giro en la valoración que socialmente se otorga a los padres adoptivos según tipo de filiación reflejaría la desvinculación, en sociedades individualizadas, de la maternidad con la construcción social de la identidad femenina y, si bien su correlato más inmediato no es la desestigmatización de la infertilidad propiamente, sí que alcanzaría la aceptación de comportamientos considerados tradicionalmente desviados, como es la infertilidad voluntaria (Alberdi y Escario, 2003: 51-54; Meil, 1999: 14; Meil, 2006: 138).

El cuadro 6 muestra cómo la vida cotidiana de las familias adoptivas aparece enmarcada por el sentimiento de que ocupan un estatus inferior, lo que puede contribuir a su percepción de que sus familias «no son reales» $\mathrm{O}$ «verdaderas». La diferenciación con la que es valorada socialmente la adopción recaería, en opinión de los encuestados, sobre su modelo de hogar y no tanto sobre sus hijos adoptados o ellos mismos como padres adoptivos. Esta consideración, aún siendo compartida, adquiere matices a partir de las vivencias particulares a las que se enfrentan las familias adoptivas según tipo de filiación y alianza. Las familias adoptivas coinciden mayoritariamente en que su modelo doméstico es juzgado socialmente como una "alternativa menos satisfactoria», pero son las familias monoparentales quienes lo reconocen con mayor intensidad (el 60,8\% frente al 54,3\% de las familias biparentales).

La mayor percepción del estigma entre las familias adoptivas monoparentales reflejaría la aportación del saber experto a la construcción social de la adopción y su impacto en las propias familias. Jociles et al. (2012: 539) han anotado que los profesionales que evalúan a las adoptantes en solitario conciben la monoparentalidad como un factor de "riesgo", tanto para el éxito de una adopción como para el desarrollo y el bienestar 
María José Rodríguez-Jaume; Diana Jareño Ruiz

Cuadro 6. Grado de acuerdo en torno a valoraciones que hace la sociedad, en general, sobre la adopción según estructura familiar adoptiva (\%)*

\begin{tabular}{|c|c|c|c|c|}
\hline & \multicolumn{3}{|c|}{ Familias biparentales } & \multirow{3}{*}{$\begin{array}{l}\text { Familias } \\
\text { monop. }\end{array}$} \\
\hline & \multirow[b]{2}{*}{ Total } & \multicolumn{2}{|c|}{ Filiación } & \\
\hline & & Adoptiva & Mixta & \\
\hline $\begin{array}{l}\text { Las personas ajenas a la adopción la consideran como } \\
\text { una alternativa menos satisfactoria de formar una } \\
\text { familia }\end{array}$ & 54,3 & 54,0 & 55,5 & 60,8 \\
\hline $\begin{array}{l}\text { La sociedad cree que los niños adoptados son niños } \\
\text { de «segunda» }\end{array}$ & 37,9 & 37,0 & 40,7 & 39,1 \\
\hline $\begin{array}{l}\text { Las personas ajenas a la adopción creen que los } \\
\text { padres adoptivos tienen menos «instinto» para cuidar } \\
\text { y criar eficazmente de sus hijos e hijas }\end{array}$ & 29,1 & 31,3 & 22,3 & 34,8 \\
\hline
\end{tabular}

Fuente: elaboración propia a partir de los datos de la encuesta Las familias adoptivas y sus estilos de vida (2012).

* El cuadro recoge el porcentaje de respuestas afirmativas ofrecidas a los valores 4 y 5 de una escala en donde 1 indicaba «nada de acuerdo» y 5, «muy de acuerdo».

Las opciones de respuesta NS y NC se han excluido del cuadro.

del niño. Estos prejuicios se sostendrían en el modelo de familia nuclear parsoniano desde el que las familias monoparentales matrifocales son vistas como «incompletas», "disfuncionales» o "deficitarias», al contravenir sus dos principios fundamentales: la biprogenitura (heterosexual) y la ausencia de jefatura masculina (proveedor principal) (Barrón, 1998: 220).

Por su parte, entre las familias biparentales, la percepción que más marca las distancias es la valoración que la sociedad hace de sus hijos adoptados, pues para un $40,7 \%$ de los padres que tienen hijos biológicos, sus hijos adoptivos son percibidos como «niños de segunda», frente al 37\% de los padres que solo tienen hijos adoptivos. Estas diferencias hay que enmarcarlas en la norma social que vincula al proyecto familiar de pareja con los hijos, de tal modo que, socialmente, vivir en pareja sin hijos es percibido como una etapa circunstancial (Alberdi y Escario, 2003: 53). En este sentido, la sociedad valoraría la adopción como la solución más óptima cuando una pareja (supuestamente) no puede tener hijos biológicos.

La experiencia de contar con hijos biológicos marca las diferencias a la hora de juzgar el «instinto» cuidador, tanto de las parejas adoptivas como de las madres adoptivas solas por elección. Son las parejas adoptivas que cuentan exclusivamente con filiación adoptiva $(31,3 \%)$ y, fundamentalmente, las madres adoptivas que han adoptado en solitario $(34,8 \%)$ quienes más expuestas se sienten a que se cuestione su capacidad, «instinto», para la atención y la crianza de sus hijos. Ambas formas familiares se ven atrapadas en la concepción biológica y naturalista de la familia (Bernardes, 1985), desde la que socialmente se construye el sentimiento de que la "genuina» y "verdadera" maternidad es la que deviene del indisoluble lazo de sangre que vincula a madres e hijos de nacimiento (Kirk, 1964). Adicionalmente, las madres adoptivas por elección se enfrentarían a situaciones en las que se presupone que su maternidad en soli- 
Cuadro 7. Razones para no adoptar según estructura familiar adoptiva $(\%)^{\star}$

\begin{tabular}{|c|c|c|c|c|}
\hline & \multicolumn{3}{|c|}{ Familias biparentales } & \multirow{3}{*}{$\begin{array}{l}\text { Familias } \\
\text { monop. }\end{array}$} \\
\hline & \multirow[b]{2}{*}{ Total } & \multicolumn{2}{|c|}{ Filiación } & \\
\hline & & Adoptiva & Mixta & \\
\hline $\begin{array}{l}\text { Un hijo o una hija adoptado no quiere de la misma } \\
\text { manera que un hijo o una hija biológico }\end{array}$ & 57,2 & 53,5 & 69,2 & 34,8 \\
\hline $\begin{array}{l}\text { Los niños y las niñas adoptados no acaban de integrar- } \\
\text { se en el entorno familiar }\end{array}$ & 45,0 & 44,1 & 48,1 & 52,2 \\
\hline $\begin{array}{l}\text { Los niños pueden tener enfermedades y problemas de } \\
\text { salud desconocidos }\end{array}$ & 41,0 & 40,6 & 42,3 & 65,2 \\
\hline $\begin{array}{l}\text { Los niños y las niñas adoptados no se parecen física- } \\
\text { mente a los padres y para ellos es importante }\end{array}$ & 40,5 & 42,4 & 34,6 & 39,1 \\
\hline $\begin{array}{l}\text { No tienen las cualidades que se requieren para afrontar } \\
\text { un proceso de adopción }\end{array}$ & 26,6 & 28,2 & 21,2 & 21,7 \\
\hline $\begin{array}{l}\text { En algún momento, su hijo o hija puede ser reclamado } \\
\text { por sus padres biológicos }\end{array}$ & 22,5 & 22,9 & 21,2 & 17,4 \\
\hline $\begin{array}{l}\text { Los niños y las niñas adoptados tienen más problemas } \\
\text { médicos que los hijas y las hijas biológicos }\end{array}$ & 20,7 & 21,8 & 17,3 & 13,0 \\
\hline $\begin{array}{l}\text { Adoptar un niño o a una niña supone un gasto econó- } \\
\text { mico muy importante }\end{array}$ & 17,6 & 17,1 & 19,2 & 21,7 \\
\hline $\begin{array}{l}\text { Tener hijos a través de la adopción va en contra de la } \\
\text { naturaleza humana }\end{array}$ & 5,4 & 6,5 & 1,9 & 4,3 \\
\hline
\end{tabular}

Fuente: elaboración propia a partir de los datos de la encuesta Las familias adoptivas y sus estilos de vida (2012).

* El cuadro recoge los porcentajes a partir del número de respuestas registradas a la pregunta de respuesta múltiple.

Las opciones de respuesta NS y NC se han excluido del cuadro.

tario es un riesgo para la crianza, el desarrollo y el bienestar del hijo adoptado (Jociles et al., 2012: 539).

Con el propósito de explorar en las dimensiones de estigmatización de la familia adoptiva, se pidió a los encuestados que identificaran las razones que sostienen quienes defienden que jamás adoptarían (cuadro 7). Las vivencias disímiles que experimentan tanto quienes afrontan la adopción en pareja como quienes lo hacen en solitario determinan sus percepciones diferentes. Así, mientras que, entre las parejas adoptivas, estas vendrían determinadas en mayor medida por la ideología biologiscista del parentesco occidental; para las familias monoparentales, la ideología de la biparentalidad de la familia nuclear cobraría mayor protagonismo. En su opinión, las razones que sustentan quienes jamás adoptarían se vinculan con la percepción de que la maternidad en solitario es un factor de riesgo para el cuidado y la atención de sus hijos adoptados, pues, se presupone, tendrán más problemas de salud $(65,2 \%)$ e integración familiar $(52,2 \%)$.

Entre las familias adoptivas biparentales, la razón que suscita más consenso alude a la creencia social de que la unión y el amor de un hijo adoptivo no es tan "genuino", a causa de la ausencia de lazos de sangre. Esta percepción es la única compartida por la mayoría de los padres que viven en pareja (el 57,2\%) y es la que más distancia a las familias adoptivas según el tipo de filiación: el 
69,2\% de las que cuentan con filiación mixta, frente al 53,5\% de las familias con filiación adoptiva. En clave sociológica, son las familias adoptivas con filiación mixta las que más estarían transgrediendo la ideología de la familia genética y, en consecuencia, las más sancionadas socialmente, pues, aún contando con la «auténtica» unión y relación filial de su hijo biológico, también optan por una filiación social.

La importancia del lazo biológico adquiere nuevamente relevancia, al compartir las familias adoptivas biparentales que la ausencia de parecido físico justificaría la decisión de no adoptar. Esta opinión, aún siendo solo manifestada por el 40,5\% de las familias adoptivas biparentales, muestra distancias según tipo de filiación. Los padres de filiación adoptiva estarían más expuestos a la sanción social que deviene de la no semejanza entre parientes (así lo reconocen el $42,4 \%$ frente al $34,6 \%$ de los padres con filiación mixta), pues en las sociedades en las que el parentesco se basa en un modelo de conexión biológica, la existencia de una «auténtica» relación filial se constata a través del símbolo de los parecidos (Marre y Bestard, 2009).

\section{Conclusiones}

El estudio de la familia adoptiva ofrece interesantes retos para la sociología de la familia, al abordar la constitución de unidades familiares que desafían el modelo normativo de la familia biológica. Bernardes (1985: 275) ha anotado que la sociología de la familia tradicional ha sido el principal baluarte de la «ideología de la familia», al hacer hincapié en los elementos tradicionales, individualistas y naturalistas de la familia moderna. La disciplina habría mitificado la vida familiar en torno a aquellos elementos en los que se ha centrado, sobre los que ha investigado. Obviar los modelos de familia posconsanguíneos (Rodríguez, 2012) restringe en el plano académico el debate sobre el alcance y los límites que conlleva aplicar el concepto canónico de familia en sociedades contemporáneas, lo que se traduce, en el plano social, en su estigmatización. La imagen de la familia que tiene el público en general, continúa Bernardes, deviene del conocimiento arrojado desde la psicología y sociología, por lo que la agenda académica debería dar prioridad al estudio de las carencias teóricas.

El perfil sociodemográfico de las madres y de los padres adoptivos espanoles de la encuesta Las familias adoptivas y sus estilos de vida no difiere del identificado en otros países: elevada formación y desarrollo de ocupaciones de mayor prestigio social, posicionados en la izquierda política, sin identificación religiosa y defensores del sistema de valores posmodernos respecto a la institución familiar, pues mantienen una opinión muy favorable hacia comportamientos familiares tradicionalmente contemplados como desviados. Las madres y los padres adoptivos se adscriben a patrones sociales tales como la centralidad del hijo en la familia y la sentimentalización de las relaciones filiales. Sin embargo, lo hacen con mayor intensidad que la población en general, con lo cual contribuyen al desarrollo de una ideología de familia basada en el funcionamiento y no en la formación. Por ello, también se diferencian en las 
opiniones que manifiestan respecto a las funciones que, personalmente, creen que debe asumir la familia. Para las familias adoptivas, su función principal es la de proveer amor y afecto, por ello relegan a un segundo plano las labores de crianza y educación.

El diseño de la encuesta ha permitido identificar la pluralización de la estructura de las familias adoptivas españolas. Al diferenciar entre familias adoptivas monoparentales y biparentales y familias adoptivas con filiación adoptiva y mixta, se avanza en tres aspectos importantes. En primer lugar, se señalan las distintas rutas de acceso a la filiación adoptiva, mostrando, a su vez, la complejidad del fenómeno y la necesidad de evitar construcciones unitarias y globalizantes en torno a la familia adoptiva. En segundo lugar, se subraya la pérdida de importancia que la descendencia consanguínea ha ido adquiriendo en los procesos de construcción identitaria individual y familiar, pues la adopción, hoy, no es solo una vía para las parejas infértiles, sino también para las personas que tienen o pueden tener hijos biológicos y para las que, aún contando con un diagnóstico de infertilidad, optan por la adopción sin agotar las posibilidades que ofrece la medicina reproductiva. Por último, y como corolario de lo expuesto, se aprecia el mayor protagonismo que, en las sociedades avanzadas, adquiere la adopción preferencial, circunstancia que contraviene la imagen social de que la adopción es «la segunda mejor opción». Esta última cuestión adquiere una relevancia especial en el proceso de construcción social de la adopción y de la familia adoptiva, pues nos introduce en el análisis de su estigmatización social, aspecto escasamente explorado en el caso español.

La mayoría de los encuestados comparten la idea de que la familia adoptiva es considerada como una forma familiar menos satisfactoria que la que produce la familia basada en lazos de sangre. Es interesante destacar que, a pesar de que se comparta esta percepción general, existen matices en las opiniones vertidas según el tipo de alianza y de filiación de las familias adoptivas. Son las familias monoparentales, que transgreden las normas de consanguinidad y biparentalidad del modelo de familia hegemónico, las que más perciben la diferenciación social. Por su parte, entre las familias adoptivas biparentales, las de filiación adoptiva sienten que la sociedad les cuestiona su «instinto" para cuidar y criar; mientras que las de filiación mixta subrayan que, socialmente, los hijos adoptados son valorados como hijos de "segunda», dado que la unión y el amor con estos no es tan «verdadero» como los de un hijo biológico. Los datos sugieren que la sociedad es más condescendiente con las familias adoptivas biparentales con filiación adoptiva. La vigencia de la norma social que vincula al proyecto familiar en pareja con la descendencia explica que la adopción sea socialmente más aceptada en los casos en los que, se presupone, no se pueden tener hijos biológicos - fácilmente reconocibles en la adopción internacional.

La estigmatización percibida por las familias adoptivas encuestadas da cuenta de la hegemonía de los lazos biológicos en la construcción social del parentesco en España. La consideración de la familia adoptiva como una forma de hogar «menos satisfactoria» transciende tanto a la agenda política como a la académica. En el plano político, la opinión pública puede limitar el desarrollo de la Ley de 
protección a la infancia (anteproyecto, 2013) con la que se busca reducir, en España, el elevado número de niños institucionalizados, potenciando dos modelos de parentesco no normativos: el acogimiento familiar y la adopción abierta. En el ámbito académico, los hallazgos expuestos enuncian futuras hipótesis de indagación. Especialmente pertinente resultaría ampliar el estudio de la percepción del estigma social de la familia adoptiva atendiendo al país de origen de los niños adoptados, así como entre las familias adoptivas homoparentales.

La diferente percepción del estigma social en las familias adoptivas según sus estructuras de alianza y filiación ha puesto de manifiesto sus múltiples realidades y, en consecuencia, la necesidad de abordar su comprensión sociológica y su conceptualización terminológica a través de investigaciones que adopten enfoques constructivistas y fenomenológicos. La perspectiva cuantitativa adoptada en la investigación ha desvelado "hechos» familiares, pero no describe a los «fenómenos» implícitos. Desde los límites de la metodología cuantitativa, la teoría de la familia posmoderna propone la participación del sujeto en el proceso de construcción conceptual de la familia, pues es a partir de la experiencia de los propios protagonistas cuando se alcanza a comprender la diversidad familiar contemporánea (Bernardes, 1985, 1993).

\section{Referencias bibliográficas}

Adoptantis (2011). El Periódico de la Adopción [en línea], 90. Madrid. <http://www.apega.org/attachments/article/447/El\%20Peri\%C3\%B3dico\%20 de\%20la\%20Adopci\%C3\%B3n.pdf> [Consulta: 9 mayo 2013].

Adroher, Salomé (1998). «La adopción internacional: Una aproximación general». En: RodRíGUez, Jesús (ed.). El menor y la familia: conflictos e implicaciones. Madrid: Universidad Pontificia de Comillas, 229-304.

Alberdi, Inés y Escario, Pilar (2003). Flexibilidad, elección y estilos de vida familiar. Madrid: Ministerio de Trabajo y Asuntos Sociales.

- (2007). Los hombres jóvenes y la paternidad. Bilbao: Fundación BBVA.

Amorós, Pere (1986). La adopción desde una perspectiva socioeducativa. Barcelona: Universitat de Barcelona.

Anderson, S.; Piantanida, M. y Anderson, C. (1993). «Normal processes in adoptive families». En: WaLsh, F. (ed.). Normal family processes. Nueva York: Guilford, 254-281.

BARRón, Sara (1998): «La construcción socio(ideo)lógica de la monoparentalidad: Ideología familiar, biparentalidad, silenciamiento y victimismo». Inguruak, 21, 203-225.

Beck, Urlich y Beck-Gernsheim, Elisabeth (2001). El normal caos del amor: Las nuevas formas de la relación amorosa. Barcelona: Paidós.

Beck-Gernsheim, Elisabeth (2003). La reinvención de la familia. Barcelona: Paidós.

Bernardes, Jon (1985). "Family ideology": Identification and exploration». The Sociological Review, 33 (2), 275-297. <http://dx.doi.org/10.1111/j.1467-954X.1985.tb00806.x>

- (1993). «Responsibilities in studying postmodern families». Journal of Family Issues, $14(1), 35-49$. <http://dx.doi.org/10.1177/0192513X93014001004> 
CIS (1995): Encuesta de Fecundidad y Familia (FFS/ONU). Mujeres. Madrid: CIS. Estudio n.o 2182.

- (2004a). Barómetro. Junio 2004. Madrid: CIS. Estudio n. ${ }^{\circ} 2.568$.

- (2004b). Opiniones y actitudes sobre la familia. Madrid: CIS. Estudio n. ${ }^{\circ} 2.578$.

- (2010). Barómetro. Septiembre 2010. Madrid: CIS. Estudio n. ${ }^{\circ} 2.844$.

Conn, Peter (2013). Adoption: A brief social and cultural history. Nueva York: Palgrave Macmillan.

Couper, Mick P. (2000). "Web surveys: a review of issues and approaches». Public Opinion Quarterly, 64 (4), 464-494.

<http://dx.doi.org/10.1086/318641>

Couper, Mick P.; Traugott, Michael W. y Lamias, Mark J. (2001). «Web survey design and administration». Public Opinion Quarterly, 65 (2), 230-253. <http://dx.doi.org/10.1086/322199>

Cho, Hyunyi y Larose, Robert (1999). «Privacy issues in internet surveys». Social Science Computer Review, 17 (4), 421-434. <http://dx.doi.org/10.1177/089443939901700402>

Davis, Mary A. (2011). Children for families or families for children. Nueva York: Springer. <http://dx.doi.org/10.1007/978-90-481-8972-4>

Delgado, Margarita (coord.) (2007). Encuesta de fecundidad, familia y valores 2006. Madrid: CIS.

Dillman, Don A. (2000). Mail and web-based survey: The tailored design method. Nueva York: John Wiley \& Sons.

FAlletti, Elena (2014). «LGBTI discrimination and parent-child relationships: cross-border mobility of rainbow families in the European Union». Family Court Review, 52 (1), 28-45. <http://dx.doi.org/10.1111/fcre.12068>

Fisher, Allen P. (2003). "Still "Not quite as good as having your own"?: Toward a sociology of adoption». Annual Review of Sociology, 29, 335-361. <http://dx.doi.org/10.1146/annurev.soc.29.010202.100209>

González, M. ${ }^{a}$ Mar; Jiménez, Irene; Morgado, Beatriz y Díez, Marta (2007). Madres solteras por elección: Análisis de la monoparentalidad emergente. Madrid: Instituto de la Mujer.

<http://redconeim.es/wp-content/uploads/downloads/2011/02/analisis-de-la-monoparentalidad-emergente.pdf> [Consulta: 17 diciembre 2013].

Haugaard, Jeffrey J. y Hazan, Cindy (2003). "Adoption as a natural experiment». Development and Psychopathology, 15 (4), 909-926. <http://dx.doi.org/10.1017/s0954579403000427>

Hoksbergen, Rene A. C. (1998). "Changes in motivation for adoption, value orientations and behavior in three generations of adoptive parents». Adoption Quarterly, 2 (2), 37-55. <http://dx.doi.org/10.1300/j145v02n02_03>

INE (2014). Medidas de protección a la infancia y adopciones [en línea]. Madrid: INE. <http://www.ine.es/jaxi/menu.do?type=pcaxis\&path=/t25/a072/a02/\&file=pcaxis $>$ [Consulta: 25 diciembre 2013].

Ishizawa, Hiromi y Kubo, Kazuyo (2013). «Factors affecting adoption decisions: Child and parental characteristics». Journal of Family Issues, 35 (5), 627-653. <http://dx.doi.org/10.1177/0192513x13514408> 
Jociles, M. a Isabel y Charro, Cristina (2008). «Construcción de los roles paternos en los procesos de adopción internacionales: El papel de las instituciones intermedias». Politica y Sociedad, 45 (2), 105-130.

Jociles, M. a Isabel; Rivas, Ana M. ${ }^{a}$ y Poveda, David (2012). «Las representaciones expertas sobre las solicitudes individuales en los procesos de adopción». Revista de Dialectología y Tradiciones Populares, LXVII (2), 535-558.

<http://dx.doi.org/10.3989/rdtp.2012.21>

Jones, J. (2008). Adoption experiences of women and men and demand for children to adopt by women 18-44 years of age in the United States, 2002: Data from National Survey of Family Grown [en línea]. Washington: National Center for Health Statistics, 23 (27).

<http://www.cdc.gov/nchs/data/series/sr_23/sr23_027.pdf> [Consulta: 10 diciembre 2013].

Juste, M. a Gracia; Ramírez, Ana y Barbadillo, Patricia (1991). Actitudes y opiniones de los españoles ante la infancia. Madrid: CIS. Estudios y Encuestas, 26.

KIRK, David (1964). Shared fate: A theory of adoption and mental health. Nueva York: Free Press. <http://dx.doi.org/10.1093/sf/43.1.120>

KreIder, Rose M. (2003). Adopted children and stepchildren: 2000 United States census. U. S. Department of Commerce Economics and Statistics Administration U. S. Census Bureau.

Kressierer, Dana K. y Bryant, Clifton D. (1996). «Adoption as deviance: Socially constructed parent-child kinship as a stigmatized and legally burdened relationship». Deviant Behavior, 17 (4), 391-415. <http://dx.doi.org/10.1080/01639625.1996.9968037>

Malm, Karin y Welti, Kate (2010). «Exploring motivations to adopt». Adoption Quarterly, 13 (3-4), 185-208. <http://dx.doi.org/10.1080/10926755.2010.524872>

March, Karen y Miall, Charlene E. (2000). "Adoption as a family form». Family Relations, 49, 359-362. <http://dx.doi.org/10.1111/j.1741-3729.2000.00359.x>

March, Martí X. (1993): La adopción en Mallorca. Palma de Mallorca: Universidad de las Islas Baleares.

Marre, Diana (2004). «La adopción internacional y las asociaciones de familias adoptantes: Un ejemplo de sociedad civil virtual global». Scripta Nova: Revista Electrónica de Geografía y Ciencias Sociales [en línea], VIII, 170 (4).

<http://www.ub.edu/geocrit/sn/sn-170-4.htm> [Consulta: 23 septiembre 2013].

- (2011). "Cambios en la cultura de la adopción y de la filiación». En: CHacón, Francisco y Bestard, Joan (dirs.). Familias: Historia de la sociedad española. Madrid: Cátedra, 893-952.

Marre, Diana y Bestard, Joan (2009). «The family body: Persons, bodies and resemblance». En: Edwards, Jeanette y Salazar, Carles (eds.). European kinship in the age of biotechnology. Oxford-Nueva York: Berghahn Books, 64-78.

MeIL, Gerardo (1999). La postmodernización de la familia española. Madrid: Acento.

- (2006). Padres e hijos en la España actual. Barcelona: Fundación 'La Caixa'.

Miall, Charlene E. (1986). "The stigma of involuntary childlessness». Social Problems, 33 (4), 268-282.

<http://dx.doi.org/10.1525/sp.1986.33.4.03a00020> 
- (1987). «The stigma of adoptive parent status: Perceptions of community attitudes toward adoption and the experience of informal social sanctioning». Family Relations, 36 (1), 34-39.

<http://dx.doi.org/10.2307/584644>

- (1996). «The social construction of adoption: Clinical and community perspectives». Family Relations, 45 (3), 309-317. <http://dx.doi.org/10.2307/585503>

MohanTy, Jayashree (2013). «Attitudes toward adoption in Singapore». Journal of Family Issues, 35 (5), 705-728.

<http://dx.doi.org/10.1177/0192513x13500962>

Ocón, José (2002). «Reflexiones en torno a la adopción por parejas homosexuales». Cuadernos de Trabajo Social, 15, 93-108.

- (2003). «Evolución y situación actual de los recursos de protección de menores en España». Revista del Ministerio de Trabajo y Asuntos Sociales, 45, 13-29.

- (2004). «Un análisis comparativo de las medidas alternativas de protección de menores en Andalucía y España». Cuadernos de Trabajo Social, 17, 63-81. <http://dx.doi.org/10.14198/altern2010.17.04>

- (2006a): «Normativa internacional de protección de la infancia». Cuadernos de Trabajo Social, 10, 113-131.

- (2006b). «Familia adoptiva y cambios en la organización familiar tradicional». Papers, 81, 171-185.

- (2008). «Aspectos psicosociales de la adopción en Andalucía». Papers, 87, 207-234.

Ocón, José y CASTÓn, Pedro (2002). "Historia y sociología de la adopción en España». RIS, 33, 173-209.

ONU (2009). Child adoption: Trends and policies. Nueva York: Organización de Naciones Unidas.

Palacios, Jesús (1997). La adopción en Andalucía. Sevilla: Consejería de Asuntos Sociales.

Palacios, Jesús; Sánchez-Sandoval, Yolanda y León, Esperanza (2005). Adopción internacional en España: Un nuevo país, una nueva vida. Madrid: Ministerio de Trabajo y Asuntos Sociales.

RALEIGH, Elizabeth (2012). «Are same-sex and single adoptive parents more likely to adopt transracially?: A national analysis of race, family structure, and the adoption marketplace». Sociological Perspectives, 55 (3), 449-471. <http://dx.doi.org/10.1525/sop.2012.55.3.449>

Rodríguez, M. a José (2012). "Las "transiciones demográficas” en la segunda modernidad». En: Geldstein, Rosa y Schufer, Marta. Problemas actuales de salud reproductiva, familia, género y sexualidad. Buenos Aires: PNUD/UNFPA y Biblos, 83-106.

Ruiz, Diego (2004). «Nuevas formas familiares». Portularia, 4, 219-230.

Selman, Peter (2006). "Trends in intercountry adoption: Analysis of data from 20 receiving countries, 1998-2004». Journal of Population Research, 23 (2), 183-204. <http://dx.doi.org/10.1007/bf03031815>

- (2009). "The rise and fall of intercountry adoption in the 21 st century». International Social Work, 52 (5), 575-594.

<http://dx.doi.org/10.1177/0020872809337681>

- (2012). «Tendencias globales en adopción internacional: ¿En el "interés superior de la infancia”?». Scripta Nova [en línea], XVI, 395 (21).

<http://www.ub.edu/geocrit/sn/sn-395/sn-395-21.htm> [Consulta: 10 diciembre2013]. 
SSI/CIR (2007). "Adopciones internacionales: Una situación cada vez más tensa». Boletín Mensual de SSI/CIR, 3.

Tyebjee, Tyzoon (2003). «Attitude, interest, and motivation for adoption and foster care». Child Welfare, 82 (6), 685-706.

Van Laningham, Jody L.; Scheuble, Laurie K. y Johnson, David R. (2012): «Social factors predicting women's consideration of adoption». Michigan Family Review, $16(1), 1-21$.

Vandivere, Sharon; Malm, Karin y Radel, Laura (2009). Adoption USA. A chartbook based on the 2007 National Survey of Adoptive Parents [en línea]. Washington D. C.: U. S. Department of Health and Human Services. Office of the Assistant Secretary for Planning and Evaluation.

<http://aspe.hhs.gov/hsp/09/nsap/chartbook/chartbook.cfm?id=2> [Consulta: 10 diciembre 2013].

Wahl, Shawn T.; Mcbride, M. Chad y Schrodt, Paul (2005). «Becoming "point and click" parents: A case study of communication and online adoption». Journal of Family Communication, 5 (4), 279-294. <http://dx.doi.org/10.1207/s15327698jfc0504_3>

WeGAR, Katarina (2000). "Adoption, family ideology, and social stigma: Bias in community attitudes, adoption research, and practice». Family Relations, 49 (4), 363370. <http://dx.doi.org/10.1111/j.1741-3729.2000.00363.x>

Zelizer, Viviana A. (1985). Pricing the priceless child: The changing social value of children. Nueva York: Princeton University Press.

<http://dx.doi.org/10.1353/jsh/20.2.398> 